\title{
Promising treatments for neuropathic pain
}

\author{
Tratamentos promissores para dor neuropática \\ Pedro Schestatsky, ${ }^{1,2,3}$, Liliane Vidor ${ }^{3,4,5}$, Pablo Brea Winckler ${ }^{1,3}$, Tatiane Gomes de Araújo ${ }^{3}$, Wolnei Caumo ${ }^{5}$
}

\begin{abstract}
In the last few years the understanding of mechanisms and, consequently, the diagnosis of neuropathic pain (NP) has becoming progressively clearer in clinical practice. However, the treatment of such condition remains challenging so far. One of the reasons for such difficulty is the diversity of mechanisms involved in NP generation and its persistency. In the present review we discuss several treatment modalities for NP that are scantily applied in daily clinical practice. For that, we collected positive clinical evidence of unusual and SECS (Safe, Easy, Cheap, and Sensible) approaches for NP. The aim of this review is not to establish the "state of the art" or rigid guidelines for NP treatment. In a different way, we only want bring new possibilities of treatment to the readers and also to motivate investigators to confirm those positive preliminary but promising results for NP reliev.
\end{abstract}

Keywords: neuropathic pain, treatment, unconventional, alternative, evidence-based medicine.

\section{RESUMO}

Nos últimos anos, a compreensão dos mecanismos e consequentemente do diagnóstico da dor neuropática (DN) têm se tornado cada vez mais claros na prática clínica. Entretanto, o tratamento desta condição continua sendo um desafio. Uma das razões para tal dificuldade é diversidade de mecanismos envolvidos na geração e perpetuação da DN. Na presente revisão, os autores discutem várias modalidades de tratamento para DN pouco utilizadas na prática clínica diária. Para isso, selecionamos evidências clínicas positivas de abordagens para DN consideradas não-convencionais e do tipo "SFBR” (Seguro, Fácil, Barato e Racional). O objetivo desta revisão não é estabelecer o "estado da arte" ou diretrizes rígidas para o tratamento da DN. Diferente disso, pretendemos apenas trazer aos leitores novas possibilidades de tratamento assim como motivar pesquisadores a confirmar estes resultados preliminares, mas promissores para o alívio da DN.

Palavras-chave: dor neuropática, tratamento, alternativo, medicina baseada em evidência.

Neuropathic pain is defined as pain caused by lesion or dysfunction of the somatosensory system ${ }^{1}$ and is most commonly consequence from several clinical conditions, such as diabetes, chemotherapy, herpes zoster infection, chronic alcohol abuse and other idiopathic conditions, such as idiopathic small fiber neuropathy and trigeminal pain. Patients with NP usually complain of burning and tingling sensations over the skin that almost always correspond to a plausible body distribution. Antidepressants and antiepileptic drugs are the mainstay of therapy, but they usually relieve only $40-50 \%$ of the pain ${ }^{2}$. Since the diagnosis of NP has becoming clearer in the last few years with the advent of new neurophysiological and histological tools, it is believed that the diversity of pathophysiological mechanism might explain the refractoriness of NP to the conventional therapeutic approaches. Therefore, several lines of investigation have been developed in parallel with the sophistication of usual drugs used in NP patients. Some of these techniques are topical, cognitive-related or even based on currents applied to critical pain regions or even to the scalp (non-invasive brain stimulation).

In the present article we aimed to show to the readers a glimpse of these lines of investigation considering the concept of SECS (Safe, Easy, Cheap, and Sensible) treatments ${ }^{3}$. For that we searched for relevant evidence-based SECS treatments in the available scientific literature.

\section{METHOD}

We searched for clinical trials in the last 20 years using the following strategy in the following databases: Medline,

\footnotetext{
${ }^{1}$ Departamento de Neurologia, Hospital de Clínicas de Porto Alegre, Universidade do Rio Grande do Sul, Porto Alegre RS, Brazil;

${ }^{2}$ Departamento de Clínica Médica, Universidade Federal do Rio Grande do Sul, Porto Alegre RS, Brazil;

${ }^{3}$ Faculdade de Medicina, Universidade Federal do Rio Grande do Sul, Porto Alegre RS, Brazil;

${ }^{4}$ Laboratory of Neuromodulation, Spaulding Rehabilitation Hospital, Harvard Medical School, Boston, USA;

${ }^{5}$ Laboratório de Dor e Neuromodulação, Hospital de Clínicas de Porto Alegre, Universidade do Rio Grande do Sul, Porto Alegre RS, Brazil.

Correspondence: Pedro Schestatsky; Rua São Francisco, 906/703; 90620-070 Porto Alegre RS, Brasil; E-mail: pedro.schestatsky@gmail.com

Conflict of interest: There is no conflict of interest to declare.
}

Received 17 March 2014; Received in final form 15 July 2014; Accepted 05 August 2014. 
Scopus, Web of Science and Google Scholar. As search strategy, we initially combined the different therapeutic modalities (Table) with the key word [Neuropathic Pain] and using the term "Randomized controlled trials" as a filter. Then, we included (a) all original articles that reported promising results of a specific treatment in humans that were not previously considered in recent guidelines for NP treatment $t^{4,5,67,8}$ and (b) articles written in English. We also excluded the following articles: (i) animal studies and (ii) articles reporting duplicate data. Because of the low number of studies for each modality, we presented the articles in a descriptive manner.

\section{RESULTS}

The therapeutic modalities for neuropathic pain will be presented according to Table.

\section{Acetyl-L-carnitine (ALC)}

We found only one study assessing the impact of ACL in neuropathic pain patients ${ }^{9}$ performed a post-hoc analysis of data from a two 52-week randomized placebo-controlled clinical diabetic neuropathy trials testing two doses of ALC: 500 and 1,000 mg/day three times a day. Intentionto-treat analysis of 1,257 patients was done. Efficacy end points were anatomopathological (biopsy), electrophysiological and clinical signs and symptoms, most notably pain. Pain as the most bothersome symptom showed significant improvement in one study and in the combined cohort taking 1,000 mg ALC. This study demonstrates that ALC treatment is efficacious in alleviating symptoms, particularly pain in patients with established diabetic neuropathy. The authors hypothesized that ALC treatment might have inhibited active fiber degeneration, as suggested by the data found in the nerve biopsy, thereby minimizing dysesthetic pain.

\section{Alpha-lipoic-acid or thioctic acid (ALA)}

Thioctic acid and alpha-lipoic acid will going to be analysed together since their pharmacological structure is nearly the same. One main study assessed the efficacy of AlphaLipoic-Acid (ALA) in the treatment of neuropathic pain in diabetic patients with distal symmetric polyneuropathy ${ }^{10}$. In a multicenter, randomized, double-blind, placebo-controlled trial, 181 diabetic patients received once-daily oral doses of $600,1,200$ and 1,800 mg or placebo for 5 weeks after a 1-week placebo run-in period. Significant improvements favoring all three ALA groups were noted for stabbing and burning pain and the patients' global assessment of efficacy. Safety analysis showed a dose-dependent increase in nausea, vomiting, and vertigo. In conclusion, an oral dose of $600 \mathrm{mg}$ once daily appears to provide the optimum risk-to-benefit ratio.

Memeo and Loiero ${ }^{11}$ studied patients with sciatica. The authors compared the ALA versus ALC. For that, they randomized, in a double-blind basis, 64 patients with low back pain and sciatica. After 60 days authors found significant improvements from baseline in neuropathy on electromyography in both groups. Nevertheless, the group of patients of ALA reported a decreased need for analgesia in comparison with those who received ALC (71.0\% vs. 45.5\%; $\mathrm{p}<0.05$ ). Therefore, ALA $600 \mathrm{mg} /$ day appears to be comparable to ALC in the treatment of sciatic pain. However, because of the small sample and lack of placebo group, further trials are needed to confirm the results.

A four-year study involving 460 diabetic patients was not able to find significant clinical results after $600 \mathrm{mg}$ oral administration of $\mathrm{ALA}^{12}$. However, a recent meta-analysis ${ }^{13}$

Table. Overview on alternative treatments for neuropathic pain.

\begin{tabular}{|c|c|c|c|c|c|c|}
\hline Treatment & Reference(s) & Year of $1^{\text {st }}$ study & Route of administration & Tolerability* & Efficacy* & Cost* \\
\hline Acetyl-l-carnitine & [9] & 2005 & Oral & +++ & + & + \\
\hline Alpha-lipoic-acid & {$[10,11,12,13]$} & 2006 & Oral & ++ & ++ & ++ \\
\hline Cannabis & [14-16] & 2005 & Oral & + & ++ & ++ \\
\hline Capsaicin $0.075 / 8 \%$ & {$[17-21]$} & 1993 & Topical & ++ & ++ & + \\
\hline Clonidine $0.1 \%$ & [22] & 2012 & Topical & +++ & + & + \\
\hline Lidocaine 5\% & [23-26] & 2003 & Topical & +++ & +++ & +++ \\
\hline Acupuncture & [27] & 2011 & Skin needling & ++ & + & ++ \\
\hline Botulinum toxin & {$[28,29]$} & 2008 & Skin needling & +++ & ++ & +++ \\
\hline TENS & [30] & 1997 & Cutaneous stimulation & +++ & + & ++ \\
\hline PENS & {$[31,32]$} & 2000 & Cutaneous stimulation & +++ & + & ++ \\
\hline Laser & [33] & 1986 & Cutaneous stimulation & +++ & + & +++ \\
\hline tDCs & {$[34-36,41]$} & 2006 & Brain stimulation & +++ & ++ & ++ \\
\hline rTMS & {$[37,38]$} & 2007 & Brain stimulation & +++ & ++ & ++++ \\
\hline Imagery & {$[39-41]$} & 2004 & Cognitive & +++ & + & ++ \\
\hline Hypnosis & [42] & 2009 & Cognitive & +++ & + & ++ \\
\hline
\end{tabular}

*Relative tolerability, efficacy and cost compared to amitriptyline (standard approach for NP), a drug with Tolerability: ++; Efficacy: +++; and Cost: +. TENS:

Transcutaneous electrical nerve stimulation; PENS: Percutaneous electrical nerve stimulation; tDCS: Transcranial direct current stimulation; rTMS:

Repetitive transcranial magnetic stimulation. 
concluded that ALA, when given intravenously at a dosage of $600 \mathrm{mg} /$ day over a period of 3 weeks, is a grade of recommendation $\mathrm{A}$, whereas the effects of oral administration after 3-5 are still unclear.

\section{Cannabis (marijuana)}

Three studies evaluated consistently the efficacy of marijuana in the treatment of neuropathic pain. Rog et al. ${ }^{14}$ assessed cannabis delivered via an oromucosal spray, as adjunctive analgesic treatment in patients with multiple sclerosis and central pain. For that, the authors conducted a randomized, double-blind, placebo-controlled, parallelgroup trial in 66 patients with such conditions. Each cannabis spray (CS) delivered $2.7 \mathrm{mg}$ of tetrahydrocannabinol and 2.5 of delta-9-cannabidiol and patients could gradually self-titrate to a maximum of 48 sprays in 24 hours. After 5 weeks of treatment sixty-four patients (97\%) completed the trial and 34 received the CS. Pain and sleep disturbances were recorded daily on an 11-point numerical rating scale. The CS was superior to placebo in reducing the mean intensity of pain and sleep disturbance and was generally well tolerated. Some patients on CS reported dizziness, dry mouth, and somnolence, but cognitive side effects were limited to long-term memory storage.

In another study ${ }^{15}$, adults with post-traumatic or postsurgical neuropathic pain were randomly assigned to receive cannabis (this time inhaled) at four potencies $(0 \%, 2.5 \%$, $6 \%$ and $9.4 \%$ of tetrahydrocannabinol) over four 14-day periods in a crossover trial. Participants inhaled a single $25 \mathrm{mg}$ dose through a pipe three times daily for the first five days in each cycle, followed by a nine-day washout period. Twentyone patients (from 23) completed the study. The average daily pain intensity was lower in the $9.4 \%$ in comparison with the $0 \%$ tetrahydrocannabinol potency group (pain intensity of 5.4 and 6.1, respectively. Preparations with intermediate potencies yielded intermediate but non-significant degrees of relief. Participants receiving 9.4\% tetrahydrocannabinol also reported improved ability to fall asleep and quality of sleep relative to $0 \%$ tetrahydrocannabinol. The most common drug-related adverse events during the period when participants received $9.4 \%$ tetrahydrocannabinol were headache, dry eyes, burning sensation in areas of neuropathic pain, dizziness, numbness and cough.

Finally, Ellis et al. ${ }^{16}$ conducted a double-blinded, placebocontrolled, crossover trial to assess the impact of smoked cannabis on neuropathic pain in HIV. Treatments were placebo and active cannabis with different potencies (between 1 and $8 \%$ Delta-9-tetrahydrocannabinol), four times a day for 5 days separated a washout of 2 weeks. Among the completers, pain relief was greater with cannabis than placebo. The main outcome was at least $30 \%$ pain relief and this was showed by a higher proportion of subjects achieving the outcome with cannabis versus placebo (0.46 vs. 0.18). Mood and daily functioning improvement were similar between groups, but the side effects were greater in the cannabis group, most of them mild and self-limited.

\section{Capsaicin}

Several randomized, double-blind, controlled studies have assessed the role of capsaicin, cream or patch, in the treatment of neuropathic pain. Watson et al. ${ }^{17}$ evaluated the efficacy of topically applied capsaicin $0.075 \%$ cream in a double-blind, vehicle-controlled study in 143 patients with chronic postherpetic neuralgia (PHN), for at least of 6 months. An open-label study for up to 2 years to assess the safety and efficacy of long-term application of topical capsaicin was also carried out. Capsaicin 0.075\% cream demonstrated a safe and effective treatment for the pain of postherpetic neuralgia. Ellison et al. ${ }^{18}$ evaluated the efficacy of $0.075 \%$ capsaicin cream during 16 weeks, four times daily, in 99 patients with postsurgical neuropathic pain in a phase III, randomized, double-blind, controlled cross-over study. The capsaicin cream after the first 8 weeks, showed $53 \%$ of pain reduction.

McCleane ${ }^{19}$ have evaluated in the analgesic efficacy of topical administration of 3.3\% doxepin hydrochloride, $0.025 \%$ capsaicin and combination of 3.3\% doxepin and $0.025 \%$ capsaicin daily, for 4 weeks in 200 patients with chronic neuropathic pain in a randomized, double-blind, placebocontrolled study. Topical application of 3.3\% doxepin, $0.025 \%$ capsaicin and 3.3\% doxepin/0.025\% capsaicin produces analgesia of similar magnitude. The combination of 3.3\% doxepin and $0.025 \%$ capsaicin produced faster analgesia.

Backonja et al. ${ }^{20}$ evaluated the efficacy and safety of capsaicin $8 \%$ dermal patch (NGX-4010) during 12-weeks in patients with PHN for at least 6 months. These patients received a single 60-minute application of NGX-4010 or a $0.04 \%$ capsaicin control patch. NGX-4010 has produced significant reduction in pain that was maintained over a 12 -week period. More recently, Backonja et al. ${ }^{21}$ assessed the efficacy, tolerability and safety of NGX-4010 in a randomized, doubleblind, controlled study with an open-label extension. Thirtyeight patients were randomized to receive a single 60-minute application of or a $0.04 \%$ capsaicin control patch. NGX-4010 appears to be tolerable, generally safe, and effective. However, the authors found variability of response, imbalances in gender and duration of PHN between the treatment groups that might have compromised the results of the study. The difficulty of blinding topical high-concentration capsaicin, NGX-4010, likewise were a limitation of all these studies.

\section{Topical clonidine}

Campbell et al. ${ }^{22}$ randomized 179 patients with painful diabetic neuropathy, 89 patients to receive $0.1 \%$ topical clonidine gel and 90 to receive placebo gel, both applied 3 times 
per day. After 12 weeks Topical clonidine gel reduced significantly the pain in the foot of those who had sensitized C fibers (measured using topical capsaicin) in comparison with the placebo gel. The authors concluded that this approach might be useful in selected patients with neuropathic pain in which peripheral sensitization predominates.

\section{Lidocaine}

To investigate whether lidocaine patch $5 \%$ treatment is also effective in postherpetic neuropathy (PHN) and in other peripheral neuropathic pain syndromes, Meier et al. ${ }^{23}$ performed a randomized, placebo-controlled, crossover study in 40 patients peripheral neuropathy of several causes. The protocol consisted in the application of at least four patches over the most painful area for 12 consecutive hours per day. Lidocaine patch $5 \%$ significantly relieved the ongoin pain and allodynia during the first $8 \mathrm{~h}$ after application with a sustained effect over a period of 1 week. The number needed to treat (NNT) to obtain one patient with more than $50 \%$ relief was 4.4. Although not directly compared with other agents, the effects of lidocaine patch $5 \%$ were comparable to topically applied capsaicin and oral treatment with gabapentin.

In order to compare 5\% lidocaine medicated plaster treatment with pregabalin in patients with PHN and patients with DPN, Baron et al. ${ }^{24}$ enrolled 55 patients with PHN and 91 with DPN in a randomized, controlled, open-label, multicentre Trial. The effects of topical 5\% lidocaine patch were superior to pregabalin (significant response in $63.0 \%$ vs. $37.5 \%$ of patients) with fewer side effects (3.9\% vs. $39.2 \%$ ).

Two other forms of lidocaine application were also studied. Kanai et al. ${ }^{25}$ examined the effectiveness of intranasal lidocaine $8 \%$ spray on paroxysmal pain in second-division trigeminal neuralgia in a randomized and open-label study. After 7 days intranasal lidocaine $8 \%$ spray significantly decreased VAS, whereas the placebo spray did not. In the same year, Tremont-Lukats et al. $^{26}$ analyzed the efficacy of IV lidocaine in patients with ongoing neuropathic pain and found that lidocaine at $5 \mathrm{mg} / \mathrm{kg} / \mathrm{h}$ was more effective than placebo at relieving neuropathic pain. The latency and the duration of the clinical effect were 4 hours.

\section{Acupuncture}

One main study with positive results was found in the literature. One hundred and two patients with severe acute pain related to herpes zoster infection were randomized by Ursini et al. ${ }^{27}$ to receive either acupuncture $(n=52)$ or standard pharmacological treatment $(n=50)$ for 4 weeks in an open-label design. Groups were comparable regarding age, sex, pain intensity at presentation and missed antiviral prescription. Both interventions were largely effective. No significant differences were observed in response rates and no serious treatment-related adverse event was observed in both groups.

\section{Botulinum toxin}

We separated two randomized double-blind crossover trial assessing the role of botulinum toxin (BTX) for the treatment of neuropathic pain. Ranoux et al..$^{28}$ performed a randomized, double-blind, placebo-controlled, parallel group study with a total of 4 visits, baseline, 4-week, 12-week and 24-week in 29 patients with focal painful neuropathies of different etiologies. The primary outcome measure was self-reported average pain intensity assessed by Brief Pain Inventory (BPI). They conclude that BTX has direct analgesic effect in patients with focal chronic neuropathic pain associated with allodynia and should be considered as part of the therapeutical arsenal. Yuan et al. ${ }^{29}$ performed a double-blind crossover trial of BTX for diabetic neuropathic pain in 18 patients. After 12 weeks, authors found a significant reduction in visual analog scale (VAS) of pain by $2.53 \pm 2.48$ when compared to placebo $0.53 \pm 1.57(\mathrm{p}<0.05)$.

\section{Transcutaneous Electrical Nerve Stimulation (TENS)}

We identified one randomized controlled trial assessing the role of TENS in neuropathic pain patients. Kumar and Marshall ${ }^{30}$ evaluated the efficacy and safety of this therapeutic modality in 31 patients with neuropathic pain and type 2 diabetes. They were randomized to receive either active or sham electrotherapy for a daily 30 minutes session in each limb during one month. They found symptomatic improvement of 15 of the 18 patients in treatment arm group and only 3 from 13 patients in the placebo group $(\mathrm{p}<0.01)$. Although positive results were found, they must be looked with caution because of open-label design of the study.

\section{Percutaneous Electrical Nerve Stimulation (PENS)}

Two studies were identified based on the similar methodology and design to approach the effect of PENS treatment for neuropathic pain. In the study of Hamza et al. ${ }^{31}$, a total of 50 patients with type 2 diabetes and peripheral neuropathic pain of $>6$ months duration involving the lower extremities were randomly assigned to receive active PENS (needles with electrical stimulation at an alternating frequency of 15 and $30 \mathrm{~Hz}$ ) and sham (needles only) for 3 weeks. Each series of treatment was administered three times a week for $30 \mathrm{~min}$. After a 1-week washout period, all patients were subsequently switched to the other modality. At the end of the study patients treated with active PENS reduced their pain from $6.2 \pm 1.0$ to $2.5 \pm 0.8$, whereas patients treated with placebo remained unchanged in their pain scores. However, one big limitation of this study, according to own authors was the difficulty of blinding that might have caused false-positive findings in favor to active treatment.

Raphael at al..$^{32}$ performed a randomized double-blind sham-controlled crossover trial on 31 patients with chronic pain with surface hyperalgesia to investigate the short-term efficacy of PENS. For the active PENS group, pain scores 
changed from 7.5 (range 6-10) before therapy to 0.5 (range 0-8.5) after therapy.

\section{Laser therapy}

Only one study evaluated the efficacy of laser in the treatment of neuropathic pain. Kreczi and Klingler ${ }^{33}$, in a randomized single blind cross-over study, evaluated the analgesic effects of laser irradiation on acupuncture points and a sham laser treatment (placebo) in a sample of 21 patients suffering from radicular and pseudoradicular pain syndromes. Mean pain levels after laser treatment were statistically significantly lower than after placebo. Pain relief lasted longer after laser treatment in 18 out of 21 patients.

\section{Transcranial direct current stimulation (tDCS)}

Three randomized controlled trials have evaluated the efficacy of transcranial direct current stimulation (tDCS) in the treatment of neuropathic pain.

Fregni et al. $^{34}$ in a randomized, double-blind, placebo-controlled, assessed the efficacy and safety of $2 \mathrm{~mA}, 20 \mathrm{~min}$ for 5 consecutive days of anodal tDCS in 17 patients with chronic central neuropathic pain due to spinal cord injury. There was a $58 \%$ pain improvement after active anodal stimulation of the motor cortex and these results were not confounded by depression or anxiety changes. Mori et al. ${ }^{35}$ assessed 19 patients with multiple sclerosis in a randomized, doubleblind, sham-controlled study to investigate the role of $2 \mathrm{~mA}$, $20 \mathrm{~min}$ for 5 consecutive days of anodal tDCS in reducing central chronic pain. The magnitude of reduction on visual analogue scale (VAS) for pain scores was $63.17 \%$, suggesting that tDCS can be a tool for the treatment of pain in patients with multiple sclerosis. Antal et al. ${ }^{36}$, in a randomized, doubleblind, placebo-controlled, applied $1 \mathrm{~mA}$ of anodal tDCS for 20 min for five consecutive days in 12 patients with therapyresistant chronic pain syndromes (trigeminal neuralgia, poststroke pain syndrome, back pain, fibromyalgia). After three to four weeks of treatment, authors saw that anodal tDCS led to a pain decrease of $37 \%$ in VAS scale.

\section{Repetitive transcranial magnetic stimulation (rTMS)}

Two randomized controlled trials were found evaluating the impact of rTMS on neuropathic pain. Saitoh et al. ${ }^{37}$ applied sham and active rTMS at different frequencies in chronic pain patients with or without brain lesions. The authors significantly reduced pain by using rTMS at frequencies of 5 and $10 \mathrm{~Hz}$ when compared with sham stimulation. This pais reduction lasts for $180 \mathrm{~min}$. A stimulation frequency of $1 \mathrm{~Hz}$ was ineffective. The effect of rTMS was greater in patients with a noncerebral lesion than those with a cerebral lesion. This study concluded that the pain is only amenable to be reduced by high-frequency (5 or $10 \mathrm{~Hz}$ ) rTMS and patients with a noncerebral lesion are the best candidates for high-frequency rTMS of the precentral gyrus.
One year later André-Obadia et al. ${ }^{38}$ performed a doubleblinded, randomized, crossover study of high-rate rTMS against placebo in 28 patients with different subtypes of neuropathic pain. Pain relief was evaluated on daily basis over the week. High-frequency, posteroanterior rTMS reduced pain scores significantly more than placebo, and this effects lasted for approximately 1 week. When obtained, pain relief was not specific of any particular type of pain, but rather reduced the global pain sensation whatever its type.

\section{Imagery}

Two studies analyzed the role of graded imagery in the alleviation of neuropathic pain, both performed in patients with complex regional pain syndrome type I (CRPS I). This condition involves cortical abnormalities similar to those observed in phantom pain and after stroke.

Moseley $^{39}$ hypothesized that mirror therapy - with activation of cortical networks without limb movement would reduce pain and swelling in patients with chronic CRPS I. To analyze that, thirteen chronic CRPS I patients were randomly allocated to a motor imagery program (MIP) or to conventional management (physical therapy and ongoing medical care). The MIP consisted of two weeks each of a hand laterality recognition task, imagined hand movements and mirror therapy. After 12 weeks, the control group was crossed-over to MIP. At the end, the author found a number needed to treat of approximately 2 for a $50 \%$ reduction in neuropathic pain scores.

Two years later, the same investigator ${ }^{40}$ extended his study to patients with phantom limb pain besides those with CRPS I. Therefore, fifty-one patients with phantom limb pain or CRPS I were randomly allocated to motor imagery in the same fashion as the previous study. After 6 months, there was a decrease in pain between pre- and post-treatment of $23.4 \mathrm{~mm}$ for the motor imagery group and $10.5 \mathrm{~mm}$ for the control group in a $100 \mathrm{~mm}$ visual analogue scale.

More recently, Soler et al. ${ }^{41}$ combined the use of another form of imagery (visual illusion) plus tDCS in order to evaluate its analgesic effects in patients with neuropathic pain following spinal cord injury. In a sham controlled, double-blind, parallel group design, 39 patients were randomized into four groups receiving tDCS with walking visual illusion or with control illusion and sham stimulation with visual illusion or with control illusion. Each patient received ten treatment sessions during two consecutive weeks. After 12 weeks, authors found that the combination of tDCS and visual illusion reduced the intensity of neuropathic pain significantly more than any of the single interventions.

\section{Hypnosis}

There was only one clinical trial on PubMed database crossing the medical subject headings (MeSH) terms Neuropathic Pain AND Hypnosis. Thirty-seven adults with 
spinal-cord injury and chronic pain were randomly assigned by Jensen at al. ${ }^{42}$ to receive 10 sessions of self-hypnosis (HYP) or EMG biofeedback relaxation (BIO) training for pain management. Patients in the HYP group, but not the BIO group, reported significant decreases in daily average pain after treatment with sustained effects after 3 months.

A recent review article ${ }^{43}$ authors suggest that pain specialist physician can learn hypnosis and utilize it on acute a chronic pain. However, the lack of well designed studies with large population makes this therapy indication still controversial.

\section{CONCLUSION}

Neuropathic pain is a very distressing symptom and its prevalence is around $8.2 \%$ in general population and is responsible for $17 \%$ for all chronic pain conditions ${ }^{44}$. Although it is a difficult condition to treat, adverse events related to the traditional approaches are very limiting. For example, $20 \%$ of patients taking pregabalin - one of the most traditional drugs for neuropathic pain - withdrew the drug because of somnolence ${ }^{45}$. In the same way, the tricyclic antidepressants - the first line treatment for NP - typically induce urinary retention and cognitive side effects that are very disabling especially for the elderly ${ }^{46}$.

With the exception of alpha-lipoic-acid and cannabis the alternative treatments displayed in the present review are very tolerable and relatively cheap. With regard to the quality of the studies, most of them showed methodological problems that preclude firm conclusions and therefore, firm recommendations for clinical practice, since the role of placebo in neuropathic pain is notorious ${ }^{47}$. Although we presented several promising approaches for the treatment of NP, some criticism should be mentioned here regarding the potential presence of biases in the abovementioned pain studies. Duration, size, and imputation are several that have been discussed widely in the past couple of years ${ }^{48}$ and their effect can be to turn a result that looks positive and statistically significant, to a result that is non-significant (or even occasionally significantly worse than placebo).

Another important aspect to be discussed is the duration of the most of studies. Is a study of a few days likely to answer a question on benefit for a given intervention in a condition that last months? All those questions might be taken into account to critical interpretation of the abovementioned and future studies on any type of pain.

Although we still recommend that relevant evidence-based guidelines should be followed ${ }^{4,5,6,7}$ pharmacological off-label options $^{8}$ taking into consideration the safety of those approaches, we strongly believe that they can be used alone or in combination in well selected cases i.e, patients that are refractory or intolerant to the conventional modalities for NP. Some modalities presented here are considered a SECS type of treatment ${ }^{3}$ - in opposed to a RUDE (risky, uneasy, difficult and expensive) approach - and therefore could be considered for treatment even without a Level Ia recommendation (Table).

In conclusion, unconventional approaches for NP are promising but further studies are justified in the future in order to replicate and confirm the impressions presented in our review.

\section{References}

1. Treede RD, Jensen TS, Campbell JN, Cruccu G, Dostrovsky JO, Griffin JW et al. Neuropathic pain: redefinition and a grading system for clinical and research purposes. Neurology. 2008;70(18):1630-5. http://dx.doi.org/10.1212/01.wnl.0000282763.29778.59

2. Schestatsky P, Nascimento OJ. What do general neurologists need to know about neuropathic pain? Arq Neuropsiquiatr. 2009;67(3A):741-9. http://dx.doi.org/10.1590/S0004-282X2009000400039

3. Hurt EA, Arnold LE, Lofthouse N. Dietary and nutritional treatments for attention-deficit/hyperactivity disorder: current research support and recommendations for practitioners. Curr Psychiatry Rep. 2011;13(5):323-32. http://dx.doi.org/10.1007/s11920-011-0217-z

4. Finnerup NB, Otto M, Jensen TS, Sindrup SH. An evidence-based algorithm for the treatment of neuropathic pain. Med Gen Med. 2007;9(2):36.

5. Attal N, Cruccu G, Baron R, Haanpää M, Hansson P, Jensen TS et al. EFNS guidelines on the pharmacological treatment of neuropathic pain: 2010 revision. Eur J Neurol. 2010;17(9):1113-e88. http://dx.doi. org/10.1111/j.1468-1331.2010.02999.x

6. Dworkin RH, O'Connor AB, Audette J, Baron R, Gourly GK, Haanpää $M L$ et al. Recommendations for the pharmacological management of neuropathic pain: an overview and literature update. Mayo Clin Proc. 2010;85(3 Suppl):S3-14. http://dx.doi.org/10.4065/mcp.2009.0649

7. Finnerup NB, Sindrup SH, Jensen TS. The evidence for pharmacological treatment of neuropathic pain. Pain. 2010;150(3):573-81. http://dx.doi.org/10.1016/j.pain.2010.06.019
8. Finnerup NB, Sindrup SH, Jensen TS. Recent advances in pharmacological treatment of neuropathic pain. F1000 Med Rep. 2010;2:52

9. Sima AA, Calvani M, Mehra M, Amato A. Acetyl-L-carnitine improves pain, nerve regeneration, and vibratory perception in patients with chronic diabetic neuropathy: an analysis of two randomized placebocontrolled trials. Diabetes Care. 2005;28(1):89-94. http://dx.doi.org/ 10.2337/diacare.28.1.89

10. Ziegler D, Ametov A, Barinov A, Dyck PJ, Gurieva I, Low PA et al. Oral treatment with alpha-lipoic acid improves symptomatic diabetic polyneuropathy: the SYDNEY 2 trial. Diabetes Care. 2006;29(11):2365-70. http://dx.doi.org/10.2165/00044011-200828080-00004

11. Memeo A, Loiero M. Thioctic acid and acetyl-L-carnitine in the treatment of sciatic pain caused by a herniated disc: a randomized, doubleblind, comparative study. Clin Drug Investig. 2008;28(8):495-500. http:// dx.doi.org/10.2165/00044011-200828080-00004

12. Ziegler D, Low PA, Litchy WJ, Boulton AJ, Vinik Al, Freeman R et al. Efficacy and safety of antioxidant treatment with $\alpha$-lipoic acid over 4 years in diabetic polyneuropathy: the NATHAN 1 trial. Diabetes Care. 2011;34(9):2054-60. http://dx.doi.org/10.2337/dc11-0503

13. Mijnhout GS, Kollen BJ, Alkhalaf A, Kleefstra N, Bilo HJ. Alpha lipoic Acid for symptomatic peripheral neuropathy in patients with diabetes: a meta-analysis of randomized controlled trials. Int J Endocrinol. 2012;2012:456279. http://dx.doi.org/10.1155/2012/456279 
14. Rog DJ, Nurmikko TJ, Friede T, Young CA. Randomized, controlled trial of cannabis-based medicine in central pain in multiple sclerosis. Neurology. 2005;65(6):812-9. http://dx.doi.org/10.1212/01.wnl.0000176753. $45410.8 b$

15. Ware MA, Wang T, Shapiro S, Robinson A, Ducruet T, Huynh T et al. Smoked cannabis for chronic neuropathic pain: a randomized controlled trial. CMAJ 2010;182(14):E694-701. http://dx.doi.org/ 10.1503/cmaj.091414

16. Ellis RJ, Toperoff W, Vaida F, Bnde G, Gonzales J, Gouaux B et al. Smoked medicinal cannabis for neuropathic pain in HIV: a randomized, crossover clinical trial. Neuropsychopharmacology 2009;34(3):672-80. http://dx.doi.org/10.1038/npp.2008.120

17. Watson CP, Tyler KL, Bickers DR, Millikan LE, Smith S, Coleman E. A randomized vehicle-controlled trial of topical capsaicin in the treatment of postherpetic neuralgia. Clin Ther. 1993;15(3):510-26.

18. Ellison N, Loprinzi CL, Kugler J, Hartfield AK, Miser A, Sloan JA et al. Phase III placebo-controlled trial of capsaicin cream in the management of surgical neuropathic pain in cancer patients. $J$ Clin Oncol. 1997;15(8):2974-80.

19. McCleane G. Topical application of doxepin hydrochloride, capsaicin and a combination of both produces analgesia in chronic human neuropathic pain: a randomized, double-blind, placebo-controlled study. Br J Clin Pharmacol. 2000;49(6):574-9. http://dx.doi.org/ 10.1046/j.1365-2125.2000.00200.x

20. Backonja M, Wallace MS, Blonsky ER, Cutler BJ, Malan P Jr, Rauck R et al. NGX-4010, a high-concentration capsaicin patch, for the treatment of postherpetic neuralgia: a randomised, double-blind study. Lancet Neurol. 2008;7(12):1106-12. http://dx.doi.org/10.1016/ S1474-4422(08)70228-X

21. Backonja MM, Malan TP, Vanhove GF, Tobias JK. NGX-4010, a highconcentration capsaicin patch, for the treatment of postherpetic neuralgia: a randomized, double-blind, controlled study with an open-label extension. Pain Med, 2010;11(4):600-8.

22. Campbell CM, Kipnes MS, Stouch BC, Brady KL, Kelly M, Schmidt WK et al. Randomized control trial of topical clonidine for treatment of painful diabetic neuropathy. Pain. 2012;153(9):1815-23. http://dx.doi. org/10.1016/j.pain.2012.04.014

23. Meier T, Wasner G, Faust M, Kuntzer T, Ochsner F, Hueppe M et al. Efficacy of lidocaine patch $5 \%$ in the treatment of focal peripheral neuropathic pain syndromes: a randomized, double-blind, placebocontrolled study. Pain. 2003;106(1-2):151-8. http://dx.doi.org/ 10.1016/S0304-3959(03)00317-8

24. Baron R, Mayoral V, Leijon G, Binder A, Steigerwald I, Serpell M. Efficacy and safety of $5 \%$ lidocaine (lignocaine) medicated plaster in comparison with pregabalin in patients with postherpetic neuralgia and diabetic polyneuropathy: interim analysis from an open-label, two-stage adaptive, randomized, controlled trial. Clin Drug Investig. 2009;29(4):231-41. http://dx.doi.org/10.2165/00044011-20092904000002

25. Kanai A, Suzuki A, Kobayashi M, Hoka S. Intranasal lidocaine 8\% spray for second-division trigeminal neuralgia. Br J Anaesth. 2006; 97(4):559-63. http://dx.doi.org/10.1093/bja/ael180

26. Tremont-Lukats IW, Hutson PR, Backonja MM. A randomized, double-masked, placebo-controlled pilot trial of extended IV lidocaine infusion for relief of ongoing neuropathic pain. Clin J Pain. 2006; 22(3):266-71. http://dx.doi.org/10.1097/01.ajp.0000169673.57062.40

27. Ursini T, Tontodonati M, Manzoli L, Polilli E, Rebuzzi C, Congedo G et al. Acupuncture for the treatment of severe acute pain in herpes zoster: results of a nested, open-label, randomized trial in the VZV Pain Study. BMC Complement Altern Med. 2011;11(1):46. http://dx. doi.org/10.1186/1472-6882-11-46

28. Ranoux D, Attal N, Morain F, Bouhassira D. Botulinum toxin type A induces direct analgesic effects in chronic neuropathic pain. Ann Neurol. 2008;64(3):274-83. http://dx.doi.org/10.1002/ana.21427
29. Yuan RY, Sheu JJ, Yu JM, Chen WT, Tseng IJ, Chang HH et al. Botulinum toxin for diabetic neuropathic pain: a randomized doubleblind crossover trial. Neurology. 2009;72(17):1473-8. http://dx.doi. org/10.1212/01.wnl.0000345968.05959.cf

30. Kumar D, Marshall HJ. Diabetic peripheral neuropathy: amelioration of pain with transcutaneous electrostimulation. Diabetes Care. 1997;20(11):1702-5. http://dx.doi.org/10.2337/diacare.20.11.1702

31. Hamza MA, White PF, Craig WF, Ghoname ES, Ahmed HE, Proctor TJ et al. Percutaneous electrical nerve stimulation: a novel analgesic therapy for diabetic neuropathic pain. Diabetes Care. 2000;23(3):365-70. http://dx.doi.org/10.2337/diacare.23.3.365

32. Raphael JH, Raheem TA, Southall JL, Bennett A, Ashford RL, Williams S. Randomized double-blind sham-controlled crossover study of short-term effect of percutaneous electrical nerve stimulation in neuropathic pain. Pain Med. 2011;12(10):1515-22. http://dx.doi.org/ 10.1111/j.1526-4637.2011.01215.x

33. Kreczi T, Klingler D. A comparison of laser acupuncture versus placebo in radicular and pseudoradicular pain syndromes as recorded by subjective responses of patients. Acupunct Electrother Res. 1986;11(3-4):207-16.

34. Fregni F, Boggio PS, Lima MC, Ferreira MJ, Wagner T, Rigonatti SP et al. A sham-controlled, phase II trial of transcranial direct current stimulation for the treatment of central pain in traumatic spinal cord injury. Pain. 2006;122(1-2):197-209. http://dx.doi.org/10.1016/j.pain. 2006.02.023

35. Mori F, Codecà C, Kusayanagi H, Monteleone F, Buttari F, Fiore S et al. Effects of anodal transcranial direct current stimulation on chronic neuropathic pain in patients with multiple sclerosis. J Pain. 2010;11(5):436-42. http://dx.doi.org/10.1016/j.jpain.2009.08.011

36. Antal A, Terney D, Kühnl S, Paulus W. Anodal transcranial direct current stimulation of the motor cortex ameliorates chronic pain and reduces short intracortical inhibition. J Pain Symptom Manage. 2010;39(5):890-903. http://dx.doi.org/10.1016/j.jpainsymman.2009.09.023

37. Saitoh Y, Hirayama A, Kishima H, Shimokawa T, Oshino S, Hirata M et al. Reduction of intractable deafferentation pain due to spinal cord or peripheral lesion by high-frequency repetitive transcranial magnetic stimulation of the primary motor cortex. J Neurosurg. 2007;107(3):555-9. http://dx.doi.org/10.3171/JNS-07/09/0555

38. André-Obadia N, Mertens P, Gueguen A, Peyron R, Garcia-Larrea L Pain relief by rTMS: differential effect of current flow but no specific action on pain subtypes. Neurology. 2008;71(11):833-40. http://dx. doi.org/10.1212/01.wnl.0000325481.61471.f0

39. Moseley GL. Graded motor imagery is effective for long-standing complex regional pain syndrome: a randomised controlled trial. Pain. 2004;108(1-2):192-8. http://dx.doi.org/10.1016/j.pain.2004.01.006

40. Moseley GL. Graded motor imagery for pathologic pain: a randomized controlled trial. Neurology. 2006;67(12):2129-34.

41. Soler MD, Kumru H, Pelayo R, Vidal J, Tormos JM, Fregni F et al. Effectiveness of transcranial direct current stimulation and visual illusion on neuropathic pain in spinal cord injury. Brain. 2010; 133(9):2565-77. http://dx.doi.org/10.1093/brain/awq184

42. Jensen MP, Barber J, Romano JM, Hanley MA, Raichle Ka, Molton IR et al. Effects of self-hypnosis training and EMG biofeedback relaxation training on chronic pain in persons with spinal-cord injury. Int J Clin Exp Hypn. 2009;57(3):239-68. http://dx.doi.org/10.1080/ 00207140902881007

43. Lee JS, Pyun YD. Use of hypnosis in the treatment of pain. Korean $J$ Pain. 2012;25(2):75-80. http://dx.doi.org/10.3344/kjp.2012.25.2.75

44. Torrance N, Smith BH, Bennett MI, Lee AJ. The epidemiology of chronic pain of predominantly neuropathic origin. Results from a general population survey. J Pain. 2006;7(4):281-9. http://dx.doi.org/ 10.1016/j.jpain.2005.11.008

45. Seventer R, Bach FW, Toth CC, Serpell M, Temple J, Murphy TK et al. Pregabalin in the treatment of post-traumatic peripheral neuropathic 
pain: a randomized double-blind trial. Eur J Neurol. 2010;17(8):1082-9. http://dx.doi.org/10.1111/j.1468-1331.2010.02979.x

46. Watson CP, Vernich L, Chipman M, Reed K. Nortriptyline versus amitriptyline in postherpetic neuralgia: a randomized trial. Neurology. 1998;51(4):1166-71. http://dx.doi.org/10.1212/WNL.51.4.1166

47. Petersen GL, Finnerup NB, Nørskov KN, Grosen K, Pilegaard HK, Benedetti $F$ et al. Placebo manipulations reduce hyperalgesia in neuropathic pain. Pain. 2012;153(6):1292-300. http://dx.doi.org/ 10.1016/j.pain.2012.03.011

48. Moore RA, Straube S, Eccleston C, Derry S, Aldington D, Wiffen P et al. Estimate at your peril: imputation methods for patient withdrawal can bias efficacy outcomes in chronic pain trials using responder analyses. Pain. 2012;153(2):265-8. http://dx.doi.org/10.1016/j.pain. 2011.10.004 